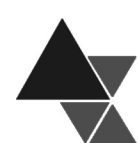

\title{
Vem cada vez mais de longe o leite nosso de cada dia: alterações recentes na cadeia dos lácteos no Estado de São Paulo
}

\author{
José Giacomo Baccarin $^{1}$ e Sany Spínola Aleixo ${ }^{2}$
}

\begin{abstract}
Nas últimas décadas uma série de transformações ampliou o alcance do mercado dos lácteos, sendo possível a captação de leite in natura em estabelecimentos distantes dos laticínios e a comercialização dos produtos processados em locais mais longínquos. $\mathrm{O}$ artigo se propõe a analisar mudanças que ocorreram na produção primária, na industrialização e no consumo do leite de vaca e seus derivados no Estado de São Paulo, entre 1990 e 2010. A pecuária leiteira paulista apresentou baixo dinamismo, fazendo com que São Paulo passasse de segundo para sexto maior Estado brasileiro produtor de leite cru ou resfriado no período. Sob o avanço da lavoura canavieira, a área de pastagem no Estado diminuiu e houve crescimento relativo da pecuária bovina de corte. Os ganhos de produtividade da pecuária leiteira paulista ocorreram em ritmo menor do que no Brasil e não foram suficientes para que se garantisse o aumento ou pelo menos a manutenção de sua produção de leite in natura. Os laticínios em São Paulo apresentaram dinamismo menor que no Brasil, embora sua produção tenha crescido além da produção primária de leite do Estado. O tamanho médio dos laticínios ficou maior e cresceu consideravelmente a produção paulista de leite longa vida, enquanto diminuía a produção do leite comercializado em embalagens de polietileno, de queijos e leite em pó. O consumo total de laticínios pelas famílias paulistas na década de 2000 aumentou, mas diminuiu o consumo per capita. A produção total de laticínios no Estado de São Paulo atende atualmente menos que $60 \%$ do seu consumo estadual total.
\end{abstract}

Palavras-chave: cadeia agroindustrial dos lácteos, Estado de São Paulo, leite.

\section{Our everyday milk comes from more and more away: recent changes in the dairy chain in the State of São Paulo}

In the last few decades a number of changes has broadened the dairy market, enabling the in natura milk collect in farms far from the dairy plants, allowing the dairy commercialization in farther places. The article aims analyze the changes happened in the milk and dairy primary production, industrialization and consumption in the São Paulo State, from 1990 to 2010. The dairy cattle production presented low dynamic, moving São Paulo State from second to sixth higher Brazilian raw and cooled milk producer in this period. With the sugarcane plantation advancing and the beef cattle farms increasing relatively, the pasture area has decreased. The São Paulo State dairy cattle productivity gains happened in a lower scale when compared to the rest of the country, being insufficient to ensure rising, or at least to the maintenance, of its in natura milk production. The São Paulo State dairy industry showed lower dynamism than the Brazil, although its production has grown beyond the state primary milk production. The dairy industry average size grew larger, increasing considerably the state UHT milk production while the polystyrene-packed milk, cheese, and powder milk production have decreased. The total

\footnotetext{
1 Professor Doutor do Departamento de Economia Rural, Faculdade de Ciências Agrárias e Veterinárias, Universidade Estadual Paulista (UNESP), Campus de Jaboticabal, SP. Correspondência: Via de Acesso Prof. Paulo Donato Castellane, s/n, Jaboticabal, SP. CEP 14884-900. Tel. (16) $3209-2634$ / PABX (16) $3209-2600$. E-mail: baccarin@fcav.unesp.br.

${ }^{2}$ Doutora em Zootecnia, UNESP, Campus de Jaboticabal, SP.
} 
dairy consumption by the São Paulo State families in the 2000s has increased, although the per capita consumption has decreased. The total dairy industry production in the state currently serves less than $60 \%$ of its total consumption.

Key-words: dairy agro-food chain, São Paulo State, milk.

\section{INTRODUÇÃO}

Uma série de mudanças tecnológicas, econômicas, sociais e demográficas impactou a cadeia dos lácteos nas últimas décadas. Entre outros fatos, ganhou importância a etapa de industrialização do produto e foi possível aumentar as distâncias tanto entre produção primária e laticínios, quanto entre estes e o consumo final dos derivados lácteos. Pode-se dizer que as restrições de ampliação espacial dos mercados leiteiros associadas, entre outros motivos, à alta perecibilidade do leite in natura, foram sendo diminuídas, de maneira expressiva, por uma série de razões que serão explicitadas adiante.

As tradicionais bacias e regiões produtoras de leite foram afetadas em suas etapas de produção primária, industrialização e consumo final. Neste artigo pretende-se verificar as modificações que ocorreram nessas etapas da cadeia de lácteos no Estado de São Paulo, especialmente aquelas posteriores a 1990.

Além da breve introdução, outras cinco seções compõem este trabalho. Na segunda, com horizonte de tempo maior, procura-se descrever as principais mudanças tecnológicas, econômicas, sociais e demográficas incidentes sobre a cadeia de lácteos no Brasil. A terceira trata da evolução da produção de leite in natura, a quarta de aspectos da industrialização de leite e a quinta de mudanças qualitativas e quantitativas do consumo de lácteos no Estado de São Paulo. Por fim, a última seção procura integrar as análises da produção primária, industrialização e consumo de leite em São Paulo e propõe algumas considerações finais. Preferiu-se tratar de questões metodológicas, especificamente as fontes dos dados, ao longo do artigo.

\section{AMPLIAÇÃO ESPACIAL DO MERCADO E OUTRAS MODIFICAÇÕES NA CADEIA DOS LÁCTEOS}

A produção de leite de vaca no Brasil, por muito tempo, apresentou-se como uma atividade secundária ou complementar nos estabelecimentos agropecuários e, no mais das vezes, com características de produção de subsistência para o atendimento do grande número de pessoas moradoras da zona rural.

Nos contratos de colonato nas fazendas de café, na virada dos séculos XIX e XX, além de outras atividades de subsistência, era autorizada a criação de duas ou três vacas leiteiras para que o colono pudesse atender ao consumo de sua família. Mesmo após a implantação do Estatuto do Trabalhador Rural, em 1963, era comum que os contratos de trabalho previssem que os empresários agropecuários fornecessem uma determinada quantidade diária de leite in natura aos seus empregados, complementando a remuneração monetária. O retiro e o retireiro, respectivamente, local de e responsável pela ordenha das vacas, eram presenças constantes na maioria dos estabelecimentos agropecuários brasileiros.

Como ainda hoje acontece em muitas regiões brasileiras, a comercialização do leite in natura tendia a ocorrer, nas primeiras décadas do Século XX, a granel e diretamente entre o pecuarista e o consumidor final, que assumia a tarefa de ferver o produto, diminuindo fortemente a possibilidade do mesmo transmitir doenças. Em decorrência da sua alta perecibilidade e da precariedade dos meios de transporte, o mercado do leite era local, com pequena abrangência espacial.

A industrialização brasileira, acelerada a partir dos anos 1930, foi acarretando importantes transformações no mercado de lácteos. Em parte, porque o grau de urbanização aumentou, dificultando cada vez mais o comércio direto entre pecuarista e consumidor final, exigindo a presença de intermediários nos canais de distribuição. Outra razão foi o desenvolvimento da indústria alimentícia e, dentro dela, do segmento de laticínios, que foi se estabelecendo como agente econômico predominante na cadeia láctea.

Os laticínios, em sua maioria de caráter regional, organizavam a captação diária do leite in natura dos seus pecuaristas fornecedores em latões de 20 a 50 
litros. Este produto passava pelo processo de pasteurização, uma parte era transformada em queijo e outros derivados e a maior parte era comercializada como leite fluido acondicionado em recipientes de vidro ou, no final da década de 1960, em embalagens descartáveis de plástico polietileno, que ganhou a denominação popular de leite "barriga mole"3.

O leite fluido pasteurizado precisa ser consumido em poucos dias, fato que limita o seu raio de distribuição, ou seja, o alcance espacial de seus mercados. Uma tentativa de superar essa limitação se deu através da produção de leite em pó que, por ser pouco perecível e não conter água, poderia ser transportado a menor custo para locais de consumo mais distantes de seu processamento industrial. Contudo, tal produto nunca conseguiu alcançar posição de destaque no consumo final da cadeia de lácteos, entre outras razões, pelo seu preço superior ao do leite fluido.

Ações públicas relevantes acompanharam o desenvolvimento da cadeia dos lácteos. Na tentativa de diminuir o poder oligopsonista dos laticínios, procurouse gerenciar sua relação com os pecuaristas, com a fixação pública de preço a ser pago pelo leite in natura. $\mathrm{Na}$ outra ponta da cadeia, fixava-se o preço do leite tipo $\mathrm{C}$ ao consumidor, no intuito de tentar conter as pressões inflacionárias e garantir o acesso a um produto considerado essencial, especialmente na alimentação das crianças. Tais medidas foram adotadas a partir de 1946. Logo adiante, em 1952, foi aprovado o Regulamento da Inspeção Industrial e Sanitária de Produtos de Origem Animal (Decreto 30.691/52) pelo Ministério da Agricultura, incluindo medidas para o leite e seus derivados [1].

De acordo com Aleixo [1], este período de organização do complexo agroalimentar, de 1946 a 1991, ficou conhecido como o da Regulamentação e foi muito criticado. Especialmente por desenvolver poucos instrumentos que assegurassem ao sistema produtivo possibilidades de crescimento e competitividade, além de revelar pouca efetividade em termos dos objetivos perseguidos, não sendo capaz de conter os preços aos consumidores e, muito menos, garantir preços adequados aos produtores.

\footnotetext{
${ }^{3}$ Essa denominação, também usada por profissionais do setor, na indústria e no comércio, especialmente no Estado de São Paulo, deve-se à maleabilidade da embalagem de plástico polietileno.
}

A partir de 1990 importantes mudanças institucionais, econômicas e tecnológicas impactaram a cadeia de lácteos no Brasil. Em 1991, o Governo Federal deixou de fixar os preços da cadeia, sob a orientação liberal de intervir o mínimo possível nos mercados.

Tal orientação também se constatou no comércio externo, com a promoção de uma rápida e ampla abertura comercial. A constituição do Mercado Comum do Sul (MERCOSUL), no começo dos anos 1990, particularmente, causou impactos significativos em algumas cadeias, entre elas a dos lácteos. Acontece que o Uruguai e a Argentina têm importantes bacias leiteiras, cujas produções passaram a concorrer mais fortemente com a produção brasileira. É importante se frisar que o comércio exterior do leite é praticamente todo composto de produtos já industrializados, com participação especial do leite em pó.

Algumas mudanças possibilitaram que a distância entre a produção de leite in natura e seu processamento industrial se ampliasse. Destaquem-se o uso de caminhões tanques com refrigeração, substituindo o transporte em latões à temperatura ambiente, as melhorias sanitárias e tecnológicas na ordenha das vacas e a implantação de tanques de resfriamento de leite nos estabelecimentos agropecuários, diminuindo a perecibilidade do produto. É bom que se diga que o acondicionamento do leite em tanques de resfriamento nos estabelecimentos agropecuários passou a ser obrigatório a partir de 2002 com a edição da Instrução Normativa Federal número 51.

Concomitantemente, evidenciou-se amplo processo de fusões e aquisições entre os laticínios, com empresas de caráter regional sendo adquiridas por empresas de atuação nacional ou mesmo transnacional. Em 2000, os dez maiores laticínios do Brasil foram responsáveis por $34 \%$ da produção de leite sob inspeção. Já em 2009, essa participação evoluiu para cerca de $42 \%$ [2]. Segundo o mesmo autor as empresas do ramo deixaram de almejar a construção de plantas com capacidade de processamento de 200 ou 300 mil litros/dia e passaram a instalar plantas com capacidade de 1 milhão de litros/dia e com elevado grau de automação, possibilitando redução do custo médio do produto industrializado. Outra reconfiguração foi o fechamento de inúmeros postos de resfriamento de leite, acompanhando a ampliação de seu transporte 
refrigerado e contribuindo também para diminuição de seu custo médio.

Em parte, o processo de concentração dos laticínios esteve e está associado ao fato de as empresas procurarem aumentar sua escala produtiva e reduzir seus custos médios, ainda mais em um mercado cuja extensão geográfica se estende e que tem grau de concorrência ampliado, entre outras razões, pela abertura comercial. Outro fato é destacado por Carvalho \& Oliveira [3], ao afirmarem que a concentração do mercado varejista de alimentos em poucas redes super e hipermercadistas afetou, especialmente, os pequenos laticínios, que não dispunham de escala de produção nem força suficiente para negociar com aquelas grandes redes, sendo excluídos do negócio e contribuindo também para a concentração dos laticínios.

Talvez, a mais significativa modificação na cadeia de lácteos no Brasil, tanto sob o ponto de vista de seu processamento industrial quanto de seu consumo final, tenha sido a implantação e a rápida disseminação do leite Ultra High Temperature (UHT), o conhecido leite longa vida ou de caixinha. Neste caso, o leite sofre um choque térmico com temperaturas mais altas que no processo tradicional de pasteurização, o que praticamente elimina seus microrganismos. Seu acondicionamento, logo a seguir, em embalagens tetrapak assegura maior facilidade de manejo aos consumidores e uma durabilidade, em temperaturas ambientes, de várias semanas ou meses. Segundo Azevedo \& Politi [4], entre o final da década de 1980 e 2004, o leite longa vida conquistou cerca de $80 \%$ do mercado de leite fluido brasileiro.

Para os laticínios, o leite longa vida possibilitou o aumento significativo no raio de comercialização do leite fluido, sem maiores riscos de perecibilidade. Para o consumidor, o leite de caixinha trouxe maior praticidade, diminuindo a necessidade quase diária de compra de leite "barriga mole" e facilitando seu manejo doméstico, na medida em que não necessita ser fervido previamente.

Outras alterações sociais e demográficas vêm impactando o consumo de leite. Em relação às segundas, destaque-se a redução da taxa de fecundidade das mulheres brasileiras e o envelhecimento médio da população, trazendo repercussões negativas sobre o consumo de leite fluido. Agindo em direção contrária, observa-se a elevação da renda média da população brasileira, o que poderia contribuir para o crescimento do consumo de leite fluido, bem como de seus derivados. Neste sentido, sofistica-se o rol de produtos lácteos consumidos pelos brasileiros, com presença de diversos tipos de queijos e de iogurtes, segundo Fonseca \& Morais [5], que constituem o segmento mais dinâmico do ramo de lácteos. Ao mesmo tempo, o desenvolvimento de outros ramos da indústria alimentícia, eleva a necessidade de produção de leite, muitas vezes em pó, a ser utilizado como matéria-prima de bolos, sorvetes, chocolates etc.

As estatísticas apontam que, entre 1990 e 2000, a produção de leite in natura no Brasil passou de $14.484,4$ para 19.767,2 milhões de litros, crescimento de $36,5 \%$ [6]. Tal expansão não foi suficiente para atender as necessidades do mercado doméstico, de forma que, no final da década de 1990, o País se transformou no terceiro maior importador de produtos lácteos do mundo. Em 1997, o saldo comercial negativo dos lácteos do Brasil atingiu US\$ 448,5 milhões, valor que se elevou para US\$506,9 milhões, em 1998 [7.

Na primeira década do Século XXI, melhorou o desempenho da produção leiteira no Brasil, alcançando 30.715,5 milhões de litros em 2010, valor $55,4 \%$ maior que a produção de 2000 [6]. A partir de 2004, registraram-se saldos positivos na balança comercial dos lácteos, com valores de US\$ 146,7 milhões, em 2007, e US\$328,4 milhões, em 2008 [7].

O crescimento da produção leiteira no Brasil nas últimas décadas decorreu, na maior parte, de fatores intensivos ou de mudanças tecnológicas nos campos da genética animal, da melhoria das pastagens e da nutrição via rações. Assim, entre 1990 e 2008, enquanto o rebanho bovino brasileiro crescia $37,5 \%$, a produção de carne bovina crescia $133,5 \%$ e a de leite bovino $90,4 \%{ }^{[8]}$. Também ocorreram melhorias sanitárias e no processo de ordenha, com crescimento da ordenha mecânica e da adoção dos tanques de resfriamento de leite pelos estabelecimentos agropecuários.

Quanto aos produtos industrializados, o desempenho dos derivados do leite foi melhor do que o do leite fluido. Assim, entre 1995 e 2005, a produção de leite fluido industrializado (pasteurizado e longa vida) cresceu $53,2 \%$ no Brasil, enquanto a produção de leite em pó crescia $61,2 \%$ e a de queijos $89,4 \%$ [ [].

\section{PRODUÇÃO DA PECUÁRIA LEITEIRA EM SÃO PAULO}


Convém iniciar esta seção com comentários sobre os dados utilizados. Uma das fontes usadas foi o Banco de Dados do Instituto de Economia Agrícola (IEA) [10] da Secretaria de Agricultura e Abastecimento do Governo do Estado de São Paulo. Anualmente se faz o "Levantamento de área e produção dos principais produtos da agropecuária do Estado de São Paulo", em que se colhem informações sobre área (ou número de pés) e produção de culturas anuais, perenes e semiperenes, frutíferas, olerícolas, produtos florestais, pecuária e criações, sericicultura e áreas de pastagens em cada um dos municípios paulistas, com a participação de técnicos da Coordenadoria de Assistência Técnica Integral (CATI), que se baseiam nos seus conhecimentos regionais. De posse dessas informações de campo, técnicos do IEA fazem o processamento, a depuração e a consolidação dos dados.

Os dados do IEA usados neste trabalho foram: uso da área em hectares pelas diferentes atividades agropecuárias e florestais, o tamanho e composição do rebanho bovino e a produção de leite de vaca.

A outra fonte de dados foram as diversas edições da Pesquisa Pecuária Municipal, levantamento anual feito em todo o Brasil pelo Instituto Brasileiro de Geografia e Estatística (IBGE), com detalhamento em nível municipal. Coletam-se informações sobre efetivos das espécies de animais criados, sobre as produções de leite, lã, ovos de galinhas e de codornas, mel e casulos de bicho-da-seda e dos preços médio pago ao produtor. Em específico sobre a produção de leite, são consideradas as quantidades comercializadas de origem do município, em postos e usinas de beneficiamento e indústrias de laticínios; pesquisa-se também a retenção média de leite para autoconsumo dos estabelecimentos produtores e o leite comercializado diretamente a consumidores que não sofreu resfriamento ou pasteurização [11].

Da Pesquisa Pecuária Municipal foram utilizadas informações do efetivo total do rebanho bovino, do número de vacas ordenhadas e da produção anual de leite.

\section{Uso da terra}

O Estado de São Paulo, desde a década de 1970, apresenta sua área rural praticamente toda utilizada por atividades agropecuárias e florestais, ou seja, não há fronteira agrícola a ser desbravada. Com isso, a expansão da área de uma atividade tende a se dar em substituição a área de outra atividade.

Nas duas últimas décadas findas, de 1990 e de 2000, um primeiro fato que pode se destacar da Tabela 1 e da Figura, é a grande expansão da área de matas naturais, especialmente na década de 1990. Não se conseguiu encontrar explicação de caráter econômico para tal fato, podendo o mesmo estar ligado a mudanças em seu levantamento pelos técnicos da CATI que, ao longo do tempo, foram se preocupando mais com essa informação. Aliás, a expansão da área de matas naturais é semelhante a que ocorreu com a área total dos estabelecimentos agropecuários no Estado.

Tabela 1. Uso da terra agropecuária e florestal no Estado de São Paulo e sua variação, de 1990 a 2010, em 1.000 hectares

\begin{tabular}{l|c|c|c|c|c|c}
\hline \multirow{2}{*}{ Tipo de Uso } & \multicolumn{3}{|c|}{ Ano } & \multicolumn{3}{c}{ Variação por período } \\
\cline { 2 - 7 } & $\mathbf{1 9 9 0}$ & $\mathbf{2 0 0 0}$ & $\mathbf{2 0 1 0}$ & $\mathbf{1 9 9 0 - 2 0 0 0}$ & $\mathbf{2 0 0 0 - 2 0 1 0}$ & $\mathbf{1 9 9 0 - 2 0 1 0}$ \\
\hline Pastagens & $10.181,1$ & $10.068,5$ & $7.810,4$ & $(112,6)$ & $(2.258,1)$ & $(2.370,7)$ \\
Matas Naturais & $1.562,4$ & $3.107,3$ & $3.379,5$ & $1.544,8$ & 272,3 & $1.817,1$ \\
Matas Plantadas & 947,6 & 890,9 & $1.151,6$ & $(56,7)$ & 260,7 & 204,0 \\
Culturas Anuais & $2.858,3$ & $2.274,6$ & $1.789,4$ & $(583,7)$ & $(485,1)$ & $(1.068,8)$ \\
Culturas Perenes & $1.388,9$ & $1.164,0$ & $1.124,3$ & $(224,9)$ & $(39,8)$ & $(264,6)$ \\
Cana-de-açúcar & $2.185,8$ & $2.908,2$ & $5.795,8$ & 722,3 & $2.887,6$ & $3.610,0$ \\
Total da Ârea & $19.124,2$ & $20.413,4$ & $21.051,1$ & $1.289,2$ & 637,7 & $1.926,9$ \\
\hline
\end{tabular}

Fonte: Instituto de Economia Agrícola (IEA) ${ }^{[10]}$. Número entre parênteses é negativo. 
Figura. Participação porcentual dos tipos de uso da área agropecuária e florestal no Estado de São Paulo, de 1990 a 2010

$\% \quad 60,00$
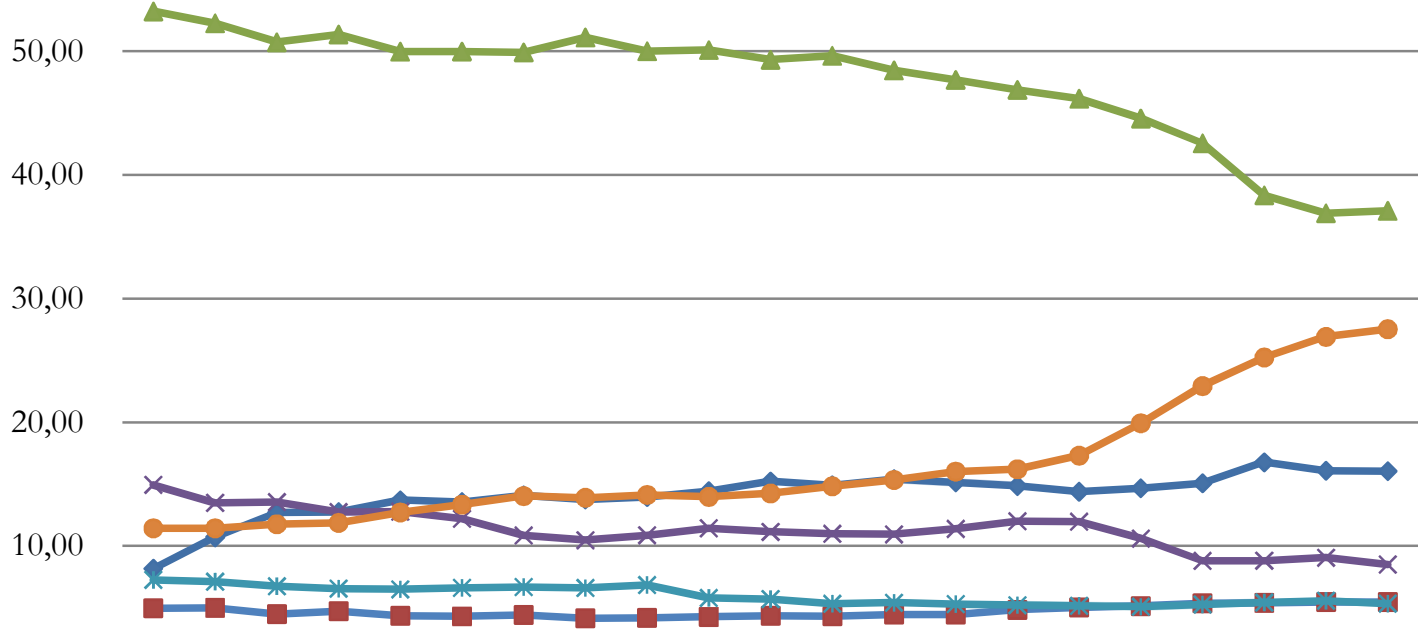

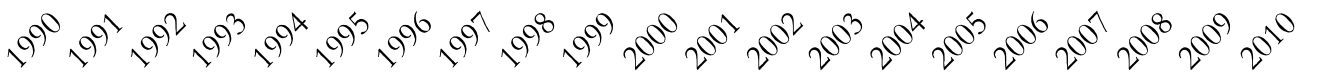

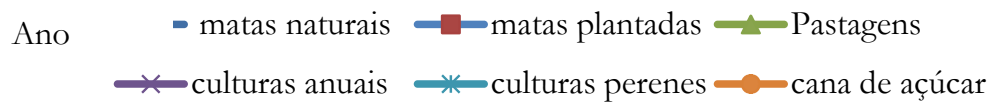

Fonte: Instituto de Economia Agrícola (IEA) ${ }^{[10] .}$

Ao longo das duas últimas décadas, a área de pastagens reduziu-se em 2.370,7 mil hectares em São Paulo, de forma muito concentrada na década de 2000. A Figura 1 mostra que em 1990, mais da metade $(53,2 \%)$ da área dos estabelecimentos agropecuários paulistas era ocupada com pastagens, passando para 49,3\%, em 2000, e caindo para 37,1\%, em 2010.

Não foram as áreas de lavouras perenes e anuais que pressionaram a área de pastagens, mesmo porque aquelas duas apresentaram redução ao longo das duas décadas analisadas. Também não houve maior pressão da expansão da área de matas plantadas, que ocorreu apenas na década de 2000 e foi relativamente pequena, na casa dos 260,7 mil hectares.

A grande responsável pela redução da área de pastagens foi a elevação da área de cana-de-açúcar, especialmente na década de 2000. Enquanto esta crescia 2.887,6 mil hectares, aquela decrescia 2.258,1 mil hectares, entre 2000 e 2010.
Perante tal redução de área de pastagens, tudo o mais constante, poder-se-ia esperar que tivesse ocorrido forte redução da produção leiteira em São Paulo. Ao menos que houvesse maior direcionamento da bovinocultura para a atividade leiteira em detrimento da atividade de corte, ou que ocorressem ganhos de produtividade no rebanho paulista.

\section{Especialização do rebanho bovino e produção de leite}

Tanto os dados do IEA como os do IBGE mostram que o rebanho bovino paulista tendeu a ser mais direcionado para a produção de carne do que para leite, entre 1990 e 2010. Assim, segundo o IEA [10], em 1990, dos 11.698.832 de bovinos no Estado, 51,9\% eram destinados ao corte, $24,6 \%$ eram de aptidão mista e 23,5\% eram rebanhos leiteiros. Já em 2010, o número de bovinos registrava uma leve redução para 11.157.300 animais, sendo $52,7 \%$ para corte, $35,9 \%$ de rebanhos mistos e apenas $11,4 \%$ com aptidão leiteira. 
A Tabela 2 mostra que o rebanho bovino em São Paulo, segundo dados do IBGE, apresentou tendência de crescimento do triênio 1990-92 a 2002-04. A partir daí passou a diminuir e, no final do período, era 9,0\% menor que em seu início. A redução do número de vacas ordenhadas, por sua vez, aconteceu, já a partir do terceiro triênio e no final mostrava-se 34,7\% inferior do que no começo. Com isso, a participação das vacas ordenhadas sobre o rebanho caiu de 18,0\% para $12,9 \%$, indicando, assim como os dados do IEA, menor direcionamento do rebanho paulista para a produção de leite.

Tabela 2. Médias anuais de triênios do total de rebanhos bovino e de vacas ordenhadas no Estado de São Paulo, 1990 a 2010

\begin{tabular}{l|ccc|c|c}
\hline \multirow{2}{*}{ Triênio } & \multicolumn{2}{|c|}{ Total de bovinos } & \multicolumn{2}{c|}{ Vacas ordenhadas } & \multirow{2}{*}{ Vacas ordenhadas/bovinos (\%) } \\
\cline { 2 - 4 } & Número & Índice & Número & Índice & \\
\hline $1990-92$ & 12.306 .276 & 100,0 & 2.214 .769 & 100,0 & 18,0 \\
$1993-95$ & 12.937 .374 & 105,1 & 2.281 .971 & 103,0 & 17,6 \\
$1996-98$ & 12.792 .494 & 103,9 & 1.972 .571 & 89,1 & 15,4 \\
$1999-01$ & 13.139 .523 & 106,8 & 1.785 .276 & 80,6 & 13,6 \\
$2002-04$ & 13.837 .694 & 112,4 & 1.704 .161 & 76,9 & 12,3 \\
$2005-07$ & 12.667 .242 & 102,9 & 1.581 .084 & 71,4 & 12,5 \\
$2008-10$ & 11.193 .619 & 91,0 & 1.447 .075 & 65,3 & 12,9 \\
\hline
\end{tabular}

Fonte: Instituto Brasileiro de Geografia e Estatística (IBGE) ${ }^{[6]}$.

A Tabela 3 mostra que nos primeiros três triênios do período estudado, enquanto a produção de leite no Brasil crescia 23,2\%, a produção paulista ficava praticamente estagnada. $\mathrm{O}$ desempenho produtivo desses dois territórios se distinguiu ainda mais nos quatro triênios seguintes, quando acentua-se o crescimento da produção nacional de leite e a produção paulista entra em decréscimo.

Tabela 3. Média anual de triênios da produção de leite in natura no Brasil e em São Paulo e participação da produção de São Paulo no Brasil, 1990 a 2010

\begin{tabular}{l|c|c|c|c|c}
\hline \multirow{2}{*}{ Triênio } & \multicolumn{2}{|c|}{ Brasil } & \multicolumn{2}{c|}{ São Paulo } & \multirow{2}{*}{ SP/BR (\%) } \\
\cline { 2 - 5 } & Mil litros & Índice & Mil litros & Índice & \\
\hline $1990-92$ & 15.115 .870 & 100,0 & 1.987 .823 & 100,0 & 13,1 \\
$1993-95$ & 15.949 .601 & 105,5 & 2.011 .423 & 101,2 & 12,6 \\
$1996-98$ & 18.625 .105 & 123,2 & 1.990 .173 & 100,1 & 10,7 \\
$1999-01$ & 19.782 .402 & 130,9 & 1.852 .647 & 93,2 & 9,4 \\
$2002-04$ & 22.457 .112 & 148,6 & 1.769 .207 & 89,0 & 7,9 \\
$2005-07$ & 25.385 .448 & 167,9 & 1.705 .202 & 85,8 & 6,7 \\
$2008-10$ & 29.128 .767 & 192,7 & 1.592 .827 & 80,1 & 5,5 \\
\hline
\end{tabular}

Fonte: Instituto Brasileiro de Geografia e Estatística (IBGE) ${ }^{[6] .}$

Em 1990-92 a produção paulista de leite representava 13,1\% da produção nacional e São Paulo era o segundo Estado produtor, sendo suplantado apenas por Minas Gerais. Já em 2008-10, aquela participação tinha caído para 5,5\% e São Paulo passava 
a ser o sexto Estado produtor, suplantado também por Paraná, Rio Grande do Sul, Goiás e Santa Catarina [1].

Enquanto que os dados do IBGE registram queda da produção paulista de leite in natura, de 19,9\%, entre 1990-92 e 2008-10, os dados do IEA indicam que a produção paulista passou de uma média anual de 1.760 milhões de litros no triênio 1990-92 para 1.971 milhões de litros no triênio 2008-10, crescimento de $12,0 \%$ [10]. Contudo, mesmo considerando as informações do IEA, o desempenho da produção leiteira paulista mostrou-se bem abaixo do brasileiro, confirmando a perda de importância de São Paulo na produção nacional.

\section{Indicadores de produtividade}

Uma das formas de se verificar o aprimoramento tecnológico da pecuária, especialmente a melhoria da qualidade nutricional dos pastos, pode ser alcançada através da análise do número de bovinos por área de pastagem, chamado de taxa de lotação. Aleixo [1], com base nos Censos Agropecuários do IBGE, indica que a taxa de lotação em São Paulo era de 1,23 bovino/hectare em 1985, passando para 1,36 em 1995/96, e alcançando 1,51 em 2006.

A Tabela 4, com dados do IEA, confirma o aumento da taxa de lotação da bovinocultura em São Paulo, de 1,15 animal/hectare, em 1990, para 1,46 animal/hectare, em 2010, elevação de 26,7\%. O crescimento da taxa foi mais expressivo na década de 2000, quando a área de pastagens reduziu-se mais bruscamente do que na década de 1990.

Tabela 4. Taxa de lotação da bovinocultura paulista, 1990 a 2010

\begin{tabular}{l|c|c|c|c}
\hline \multirow{2}{*}{ Ano } & \multirow{2}{*}{ Número de bovinos } & \multirow{2}{*}{$\begin{array}{c}\text { Área de Pastagens } \\
\text { (hectares) }\end{array}$} & \multicolumn{2}{c}{ Taxa de Lotação } \\
\cline { 4 - 5 } & 11.698 .832 & 10.181 .118 & Bovinos/hectare & Índice \\
\hline 1990 & 12.838 .417 & 10.485 .685 & 1,15 & 100,0 \\
1995 & 12.901 .962 & 10.068 .492 & 1,22 & 106,5 \\
2000 & 14.072 .447 & 10.010 .491 & 1,28 & 111,5 \\
2005 & 11.373 .083 & 7.810 .430 & 1,41 & 122,3 \\
2010 & & & 1,46 & 126,7 \\
\hline
\end{tabular}

Fonte: Instituto de Economia Agrícola (IEA) ${ }^{[10]}$.

Outro indicador de mudanças tecnológicas é a produção média por vaca ordenhada. Este indicador de produtividade capta avanços, entre outras variáveis, na genética e na nutrição animal. A Tabela 5 registra sua evolução em São Paulo e no Brasil. Enquanto no País este indicador aumentou em 71,3\%, em São Paulo o crescimento foi bem menor, de $22,6 \%$.

Tabela 5. Médias anuais de triênios da produção de leite in natura por vaca ordenhada no Brasil e no Estado de São Paulo, 1990 a 2010

\begin{tabular}{l|c|c|c|c}
\hline \multirow{2}{*}{ Triênio } & \multicolumn{2}{|c|}{ Brasil } & Litros/Vaca & Índice \\
\cline { 2 - 4 } & Litros/Vaca & Índice & 897 & 100,0 \\
$1990-92$ & 761 & 100,0 & 881 & 98,2 \\
$1993-95$ & 788 & 103,5 & 1.009 & 112,5 \\
$1996-98$ & 1.104 & 145,0 & 1.037 & 115,6 \\
$1999-01$ & 1.109 & 145,6 & 1.038 & 115,6 \\
$2002-04$ & 1.159 & 152,2 & 1.078 & 120,1 \\
$2005-07$ & 1.214 & 159,4 & 1.101 & 122,6 \\
$2008-10$ & 1.304 & 171,3 & & \\
\hline
\end{tabular}

Fonte: Instituto Brasileiro de Geografia e Estatística (IBGE) ${ }^{[6]}$. 
Os dados até aqui analisados permitem inferir que a redução da área de pastagens em São Paulo foi, praticamente, compensada pelo aumento da taxa de lotação da bovinocultura no Estado. Contudo, a produção de leite foi impactada e apresentou redução. Em parte, porque tendeu a se fortalecer a pecuária de corte em São Paulo em detrimento da pecuária de leite. Em outra parte e, provavelmente, associada à primeira, porque a evolução da produtividade (litros de leite por vaca ordenhada) no Estado de São Paulo foi pequena, em comparação com o que ocorreu no Brasil.

\section{A INDUSTRIALIZAÇÃO DO LEITE EM SÃO PAULO}

Nem todo leite produzido nos estabelecimentos agropecuários acaba por ser industrializado nos laticínios. Segundo a publicação Leite Brasil [?], a produção primária de leite em São Paulo em 2005 teve os seguintes destinos: 84,4\% para os laticínios, 3,2\% para autoconsumo nos estabelecimentos agropecuários, $0,8 \%$ para o consumo dos bezerros e 11,6\% foram vendidos diretamente aos consumidores, sem transformação industrial e sem passar por inspeção sanitária. Podese supor que, no começo do período aqui analisado (1990), a porcentagem da venda de leite não inspecionada era maior que os praticamente $12 \%$ constatado em 2005, embora não se conheçam estimativas de seu valor.

Outra observação é que as empresas de laticínios instaladas em determinado Estado não contam, necessariamente, apenas com o fornecimento de matéria-prima (leite cru ou resfriado) por agricultores do próprio Estado. No caso de São Paulo, pode-se supor que se obtenha leite in natura especialmente de Estados vizinhos, como Paraná, Mato Grosso do Sul, Goiás, Minas Gerais e Rio de Janeiro.

Ao procurar estatísticas oficiais sobre a industrialização do leite, depara-se com uma mudança metodológica no período analisado. Até 1996, o IBGE promovia a Pesquisa Mensal do Leite [12] e, a partir de 1997, passou a ser realizada a Pesquisa Trimestral do Leite [13]. A Pesquisa Mensal do Leite coletava uma série de informações sobre recebimento de leite cru ou resfriado e seu processamento apenas pelos laticínios inspecionados pelo Serviço de Inspeção Federal (SIF) ou por órgãos similares de atuação estadual e municipal [11]. Os estabelecimentos considerados como unidades de investigação, na Pesquisa Trienal, são os que adquirem o leite cru ou resfriado e o industrializam, como as usinas de pasteurização e beneficiamento, as fábricas de laticínios e as microusinas.

Tanto a primeira quanto a segunda pesquisa permitem obter informações da produção anual de leite industrializado, mas, como o próprio IBGE reconhece, elas não devem ser comparadas [11]. Embora não se explicite oficialmente a razão, como se verá adiante, a Pesquisa Mensal resultava em valores anuais sistematicamente maiores do que os da Pesquisa Trimestral. Diante da dificuldade de comparação das duas pesquisas, com apenas uma exceção, a análise ficará restrita ao período 1997-2010.

\section{Volume de leite industrializado}

A Tabela 6 mostra que no começo da década de 1990, a indústria de laticínios no Brasil e em São Paulo teve sua produção afetada, diminuindo a quantidade de leite recebida e, portanto, industrializada ${ }^{4}$. Isto se deu, provavelmente, sob os efeitos da abertura comercial e da criação do MERCOSUL. De 1994 em diante, influenciada positivamente pelo controle da inflação e por ganhos reais de salários, fica nítida uma considerável recuperação da produção dos laticínios no Brasil, fato bem menos marcante no caso do Estado de São Paulo. No período 1990-96, esse Estado perdeu importância na industrialização de leite no Brasil.

Na Tabela 7 é registrado grande crescimento da industrialização brasileira de leite, que praticamente dobrou no período 1997-2010, enquanto o aumento em São Paulo foi bem menos expressivo, na casa dos $22,3 \%$. Se em 1990, os laticínios paulistas eram responsáveis pelo processamento de $22,9 \%$ do leite no Brasil, em 2010 este número havia se reduzido para $11,0 \%$, um pouco menos da metade do valor inicial. 
Tabela 6. Leite cru ou resfriado recebido pela indústria, de acordo com a Pesquisa Mensal do Leite, Brasil e São Paulo, 1990 a 1996

\begin{tabular}{l|c|c|c|c|c}
\hline \multirow{2}{*}{ Ano } & \multicolumn{2}{|c|}{ Brasil } & \multicolumn{2}{c|}{ São Paulo } & \multirow{2}{*}{ SP/BR (\%) } \\
\cline { 2 - 5 } & Mil litros & Índice & Mil litros & Índice & \\
\hline 1990 & 10.798 .340 & 100,0 & 2.469 .890 & 100,0 & 22,9 \\
1991 & 10.487 .471 & 97,1 & 2.335 .910 & 94,6 & 22,3 \\
1992 & 10.733 .322 & 99,4 & 2.452 .908 & 99,3 & 22,8 \\
1993 & 10.143 .816 & 93,9 & 2.301 .729 & 93,2 & 22,7 \\
1994 & 10.538 .751 & 97,6 & 2.308 .240 & 93,5 & 21,9 \\
1995 & 11.792 .799 & 109,2 & 2.379 .152 & 96,3 & 20,2 \\
1996 & 12.737 .777 & 118,0 & 2.377 .524 & 96,3 & 18,7 \\
\hline
\end{tabular}

Fonte: Instituto Brasileiro de Geografia e Estatística (IBGE) ${ }^{[12] .}$

Tabela 7. Leite cru ou resfriado recebido pela indústria, de acordo com a Pesquisa Trimestral do Leite, Brasil e São Paulo, 1997 a 2010

\begin{tabular}{l|c|c|c|c|c}
\hline \multirow{2}{*}{ Ano } & \multicolumn{2}{c|}{ Brasil } & \multicolumn{2}{c|}{ São Paulo } & \multirow{2}{*}{ SP/BR (\%) } \\
\cline { 2 - 4 } & Mil litros & Índice & Mil litros & Índice & \\
\hline 1997 & 10.686 .289 & 100,0 & 1.894 .168 & 100,0 & 17,7 \\
1998 & 10.995 .373 & 102,9 & 1.848 .501 & 97,6 & 16,8 \\
1999 & 11.145 .890 & 104,3 & 1.860 .143 & 98,2 & 16,7 \\
2000 & 12.107 .741 & 113,3 & 2.132 .670 & 112,6 & 17,6 \\
2001 & 13.212 .445 & 123,6 & 2.178 .437 & 115,0 & 16,5 \\
2002 & 13.218 .929 & 123,7 & 2.383 .167 & 125,8 & 18,0 \\
2003 & 13.627 .206 & 127,5 & 2.352 .902 & 124,2 & 17,3 \\
2004 & 14.495 .146 & 135,6 & 2.408 .591 & 127,2 & 16,6 \\
2005 & 16.284 .268 & 152,4 & 2.299 .860 & 121,4 & 14,1 \\
2006 & 16.669 .743 & 156,0 & 2.113 .704 & 111,6 & 12,7 \\
2007 & 17.888 .644 & 167,4 & 2.226 .374 & 117,5 & 12,4 \\
2008 & 19.285 .077 & 180,5 & 2.294 .277 & 121,1 & 11,9 \\
2009 & 19.601 .655 & 183,4 & 2.113 .820 & 111,6 & 10,8 \\
2010 & 20.975 .503 & 196,3 & 2.316 .076 & 122,3 & 11,0 \\
\hline
\end{tabular}

Fonte: Instituto Brasileiro de Geografia e Estatística (IBGE) ${ }^{[13] .}$

A diminuição na participação de São Paulo na industrialização brasileira do leite, embora muito forte, é menor do que a queda de participação paulista na produção nacional de leite in natura, fato confirmado pela comparação das Tabelas 6 e 7 com a Tabela 3.

A Tabela 8 mostra a relação entre produção primária e industrialização do leite no Estado. Nos anos iniciais, a produção de leite in natura paulista atendia, com pequena sobra, as necessidades de matéria-prima dos laticínios paulistas, enquanto que no final se constatava um déficit de praticamente $30 \%$ na produção pecuária de leite no Estado.
Segundo a publicação Leite Brasil [9], dos 2.155 milhões de litros de leite recebidos em 2005 pelos laticínios paulistas sob inspeção do SIF e do Sistema de Inspeção de São Paulo (SISP), 687 milhões de litros, ou $31,9 \%$, vieram de outros Estados, com Minas Gerais participando com $81,4 \%$ deste total e Paraná com 11,4\%. Como informação complementar, no mesmo ano, o Estado de São Paulo enviou 58 milhões de litros de leite in natura para processamento em outros Estados. 
Tabela 8. Relação entre produção de leite in natura e leite cru ou resfriado recebido pela indústria, em mil litros, Estado de São Paulo, 1997 a 2010

\begin{tabular}{l|c|c|c}
\hline \multicolumn{1}{c}{ Ano } & Leite in natura & Leite recebido & Leite in natura/ Leite recebido (\%) \\
\hline 1997 & 2.003 .166 & 1.894 .168 & 105,7 \\
1998 & 1.981 .967 & 1.848 .501 & 107,2 \\
1999 & 1.913 .499 & 1.860 .143 & 102,9 \\
2000 & 1.861 .425 & 2.132 .670 & 87,3 \\
2001 & 1.783 .017 & 2.178 .437 & 81,8 \\
2002 & 1.783 .017 & 2.383 .167 & 74,8 \\
2003 & 1.785 .209 & 2.352 .902 & 75,9 \\
2004 & 1.739 .397 & 2.408 .591 & 72,2 \\
2005 & 1.744 .179 & 2.299 .860 & 75,8 \\
2006 & 1.744 .008 & 2.113 .704 & 82,5 \\
2007 & 1.627 .419 & 2.226 .374 & 73,1 \\
2008 & 1.588 .943 & 2.294 .277 & 69,3 \\
2009 & 1.583 .882 & 2.113 .820 & 74,9 \\
2010 & 1.605 .657 & 2.316 .076 & 69,3 \\
\hline
\end{tabular}

Fonte: Instituto Brasileiro de Geografia e Estatística (IBGE) ${ }^{[11,13]}$.

Embora possa se estabelecer que a produção industrial conseguiu um certo descolamento da produção primária de leite no Estado de São Paulo, com captação do produto em Estados vizinhos, é necessário se reconhecer que ele não é pleno. A produção dos laticínios paulistas, em termos nacionais, foi relativamente pouco dinâmica, indicando que a proximidade de fornecedores de leite in natura ainda permanece como um importante fator de competitividade desse ramo industrial.

\section{Tipos e concentração dos laticínios}

O fenômeno já descrito de concentração dos laticínios no Brasil em unidades maiores também ocorreu em São Paulo e fica evidenciado na Tabela 9. Enquanto o seu número reduziu-se em 36,8\%, seu tamanho médio aumentou em 93,5\%, entre 1997 e 2010.

Aleixo [1] aponta que dos 269 laticínios registrados em 1997 em São Paulo, 153 estavam cadastrados no SIF, 113 no SISP e apenas três em algum Sistema de Inspeção Municipal (SIM). Já em
2010, os laticínios com SIF tinham se reduzido para 79, com SISP para 75, enquanto aumentava aqueles com SIM para 16. Estes dois últimos caracterizam-se por serem de porte menor, com industrialização média diária, em 2010, de 3.542,1 litros, os com SISP, de $2.447,3$ litros, os com SIM, enquanto os com SIF apresentavam capacidade média diária de 76.239,9 litros e eram responsáveis pelo processamento de $95,2 \%$ do leite industrializado no Estado de São Paulo com algum tipo de inspeção sanitária.

Portanto, o grande predomínio de plantas maiores é bastante evidente no Estado. Contudo, são plantas que, em média, captam quantidade de leite bem abaixo de 1 milhão de litros por dia, conforme o que Carvalho [2] projeta como meta para os grandes laticínios. Outra fonte aponta que, em 2005, dos 105 laticínios com SIF em São Paulo, apenas 15 recebiam mais que 100 mil litros diários de leite, embora processassem $71,9 \%$ do total de leite recebido por esses laticínios [9]. É importante frisar que a quantidade de leite recebida tende a se situar muito aquém da capacidade potencial de produção, dada a grande ociosidade entre os laticínios [2]. 
Tabela 9. Evolução do número de unidades de laticínios e de sua média diária de recebimento de leite, Estado de São Paulo, 1997 a 2010

\begin{tabular}{l|c|c|c|c}
\hline \multirow{2}{*}{ Triênio } & \multicolumn{2}{c|}{ Unidade de processamento } & \multicolumn{2}{c}{ Média diária - recebimento leite } \\
\cline { 2 - 5 } & Número & Índice & Litros & Índice \\
\hline 1997 & 269 & 100,0 & 19.291 & 100,0 \\
1998 & 254 & 94,4 & 19.938 & 103,3 \\
1999 & 241 & 89,6 & 21.146 & 109,6 \\
2000 & 226 & 84,0 & 25.853 & 134,0 \\
2001 & 225 & 83,6 & 26.525 & 137,5 \\
2002 & 221 & 82,2 & 29.544 & 153,1 \\
2003 & 212 & 78,8 & 30.407 & 157,6 \\
2004 & 209 & 77,7 & 31.573 & 163,7 \\
2005 & 208 & 77,3 & 30.293 & 157,0 \\
2006 & 191 & 71,0 & 30.319 & 157,2 \\
2007 & 181 & 67,3 & 33.699 & 174,7 \\
2008 & 174 & 64,7 & 36.124 & 187,2 \\
2009 & 170 & 63,2 & 34.066 & 176,6 \\
2010 & 170 & 63,2 & 37.325 & 193,5 \\
\hline
\end{tabular}

Fonte: Instituto Brasileiro de Geografia e Estatística (IBGE) ${ }^{[13]}$.

Ao contrário do ocorrido no Brasil, conforme citado na seção 2 do artigo, a produção paulista de lácteos parece ter evoluído favorecendo produtos menos processados. Considerando-se apenas os laticínios com SIF, a produção de leite em pó no Estado caiu 21,9\% entre 1995 e 2005, a de queijos diminuiu em $18,5 \%$ e a redução da produção do leite fluido (pasteurizado e UHT) foi menos significativa, de 14,5\%. Contudo, especificando-se a produção do leite longa vida, observa-se crescimento de 166 milhões de litros para 841 milhões de litros no Estado, entre 1995 e 2005, 406,6\% a mais, enquanto o acréscimo da produção brasileira foi de $276,4 \%$ [ [9].

Ao mesmo tempo em que se concentram, os grandes laticínios têm adotado a política deliberada de diminuir o número e aumentar o tamanho médio de seus fornecedores de leite in natura, reduzindo custos logísticos. Assim, entre 1999 e 2009, o número de fornecedores dos 10 maiores laticínios brasileiros caiu de 130 mil para 75 mil, enquanto sua produção média diária passava de 100 para 250 litros de leite [2]. Tal fato, muito provavelmente, se repetiu no caso do Estado de São Paulo.

\section{HÁBITOS DE CONSUMO FAMILIAR DE LÁCTEOS}

A mais abrangente fonte de informações sobre hábitos de consumo, inclusive alimentar, no Brasil é a Pesquisa de Orçamentos Familiares (POF) do IBGE, cuja última edição é a de 2008-09. Este tipo de pesquisa é relativamente recente, sendo que sua primeira realização, com o nome de Estudo Nacional de Despesa Familiar (ENDEF), ocorreu em 1974-75, com abrangência nacional, exceto nas áreas rurais das regiões Norte e Centro-Oeste. Em 1987-88 e 1995-96 foram feitas POFs nas regiões metropolitanas de Belém, Fortaleza, Recife, Salvador, Belo Horizonte, Rio de Janeiro, São Paulo, Curitiba e Porto Alegre, no Município de Goiânia e no Distrito Federal. Mais recentemente, realizaram-se POFs em 2002-03 [14] e a já citada de 2008-09, com abrangência nacional [15]. Estas duas últimas edições serão usadas no presente artigo, já que permitem analisar algumas (não todas) informações para as unidades da federação, entre elas o Estado de São Paulo.

A POF permitiu que se estudasse as mudanças qualitativas no consumo dos derivados do leite e deu base para que se estimasse o consumo familiar per capita do leite pelos paulistas. Neste caso, conforme Aleixo [1], foi realizada a conversão de toda a demanda de leite fluido e seus derivados em somente leite fluido, com base em uma tabela de conversão presente na Resolução número 4.079, de 6 de março de 2009, da 
Secretaria de Estado de Fazenda do Governo de Minas Gerais, que estabelece procedimentos para a apropriação do crédito relativo à entrada de leite adquirido com o tratamento tributário a que se referem os artigos 207-A e 461 da Parte 1 do Anexo IX do Regulamento do Imposto sobre a Circulação de Mercadorias e Serviços (ICMS).

Como esse imposto taxa de diferentes formas os diversos derivados lácteos, a tabela de conversão precisa ser utilizada para a conferência a cerca da entrada de leite fluido e saída dos processados da indústria, possibilitando a conversão do consumo de leite fluido e derivados em somente leite fluido" (ALEIXO, 2012, p. 122) [1].

É necessário que se esclareça o que se está chamando de consumo familiar, que é o realizado a partir das despesas diretas das famílias, no âmbito ou fora do domicílio, de leite e de seus derivados (queijos, leite em pó, iogurte, etc.). Nesta estimativa, fica de fora, por exemplo, o consumo realizado em ações institucionais, como a Alimentação Escolar, bem como o consumo industrial de leite para produção de produtos que não se encaixam no grupo dos laticínios como sorvetes, bolos e outros da Indústria Alimentícia.

Além da POF, usaram-se informações dos Censos Demográficos do IBGE para se estimar o consumo total de leite pelos paulistas.

\section{Mudanças qualitativas}

O processo acelerado de urbanização no Brasil, em especial no Estado de São Paulo, trouxe, como uma de suas consequências, as dificuldades de deslocamento nas cidades maiores e, portanto, a elevação dos gastos das famílias com refeições fora do domicilio, especialmente no almoço. Assim, a POF 2002-03 mostrava que $74,9 \%$ das despesas com alimentação eram realizadas no domicílio e $24,1 \%$ fora do domicilio, valores que se alteraram, respectivamente, para 68,9\% e 31,1\%, conforme a POF 2008-09 [14,15]. Para a Região Sudeste, as despesas com alimentação fora do domicílio em 2002-03 representavam 26,9\% das despesas totais com alimentação, valor que passou para 37,2\% em 2008-09. São estes valores que serão aqui considerados já que não estão disponíveis os valores específicos para São Paulo, cuja importância da alimentação fora do domicílio deve ser maior que o da Região Sudeste como um todo.
As diversas edições da POF permitiam estimar a despesa monetária e o consumo físico (em peso) dos alimentos nos domicílios, enquanto que para o consumo fora do domicílio era apresentada apenas a despesa monetária. A POF 2008-09 trouxe uma inovação, como resultado de demanda específica do Ministério da Saúde, que foi a estimativa do consumo físico dos alimentos fora do domicílio. No caso dos laticínios, a quantidade relativa consumida fora do domicílio é bem menor que os 31,1\% das despesas com alimentação realizadas fora do domicílio. Assim, para o leite integral, apenas 5,8\% eram consumidos fora dos domicílios, de queijos $9,5 \%$ e de iogurtes $12,0 \%$ [15].

Ponderando-se esses e outros laticínios, calcula-se que seu consumo relativo médio brasileiro fora dos domicílios alcançou 9,0\% em 2008-09. Diante da inexistência da informação específica, supôs-se que na Região Sudeste a relação entre consumo fora do domicílio e total dos laticínios era de 10,8\%, cálculo feito levando-se em conta a relação entre despesa total com alimentação fora do domicílio no Sudeste e no Brasil. Supôs-se também que a evolução do consumo dos laticínios fora dos domicílios seguiu a taxa de crescimento da despesa total com alimentação fora do domicílio, estimando-se que seu valor, em 2002-03, era de $7,8 \%$ na Região Sudeste.

A Tabela 10 mostra a evolução no consumo domiciliar per capita dos laticínios pelos paulistas na primeira década do Século XXI. Deve-se entender que a tabela soma o peso de produtos diferenciados, o que não deixa de ser uma impropriedade. Considerando-se essa observação, percebe-se uma queda importante no consumo domiciliar de laticínios em São Paulo, na casa dos 13,1\%, de 61,92 kg, em 2002-03, para 53,84 kg, em 2008-09.

Acrescentando aos dados da Tabela 10 a estimativa do consumo de lácteos fora do domicílio, conforme valores já expressos, estima-se que, em 200203, o consumo per capita total de lácteos (dentro e fora do domicílio) pelos paulistas alcançava $67,17 \mathrm{~kg}$, passando para 60,36 kg em 2008-09, diminuição de $10,1 \%$.

A Tabela 10 mostra que a queda no consumo de laticínios está concentrada no subgrupo leite e creme de leite. Neste caso, merece ser destacada a diminuição no consumo de leite fluido (leite de vaca fresco mais leite de vaca pasteurizado), de 53,29 $\mathrm{kg}$ para 44,57 kg, 
Tabela 10. Aquisição alimentar domiciliar per capita anual por grupo e subgrupos de produtos lácteos, em quilogramas, 2002-03 e 2008-09, no Estado de São Paulo

\begin{tabular}{l|c|c|c}
\hline \multicolumn{1}{c|}{ Produto } & $\mathbf{2 0 0 2 - 0 3}$ & $\mathbf{2 0 0 8 - 0 9}$ & Variação (\%) \\
\hline Laticínios & 61,92 & 53,84 & $-13,1$ \\
Leite e creme de leite & 55,90 & 47,37 & $-15,2$ \\
Creme de leite & 0,43 & 0,46 & 5,6 \\
Leite condensado & 0,90 & 0,90 & 0,0 \\
Leite de vaca fresco & 6,64 & 2,46 & $-63,0$ \\
Leite de vaca pasteurizado & 46,65 & 42,07 & $-9,8$ \\
Leite em pó desengordurado & 0,05 & 0,03 & $-33,3$ \\
Leite em pó integral & 0,14 & 0,32 & 136,3 \\
Leite em pó não especificado & 0,30 & 0,02 & $-92,7$ \\
Outros leites e cremes & 0,80 & 1,12 & 40,7 \\
Queijos e requeijão & 2,52 & 2,57 & 2,1 \\
Queijo minas & 0,53 & 0,58 & 8,7 \\
Queijo mozarela & 0,95 & 1,10 & 15,4 \\
Queijo não especificado & 0,17 & 0,04 & $-76,4$ \\
Queijo parmesão & 0,09 & 0,12 & 41,4 \\
Queijo prato & 0,26 & 0,19 & $-24,9$ \\
Outros queijos & 0,14 & 0,12 & $-12,9$ \\
Requeijão & 0,37 & 0,42 & 11,0 \\
Outros laticínios & 3,51 & 3,90 & 11,0 \\
Iogurte & 2,51 & 2,60 & 3,5 \\
Leite fermentado & 0,68 & 1,09 & 59,6 \\
Manteiga & 0,25 & 0,19 & $-25,3$ \\
Outros & 0,07 & 0,03 & $-60,0$ \\
\hline Fonte Insing & & \\
\hline
\end{tabular}

Fonte: Instituto Brasileiro de Geografia e Estatística (IBGE) ${ }^{[14,15]}$.

ou $20,8 \%$ a menos. Especificamente, a queda do consumo de leite de vaca fresco foi muito mais significativa que do leite pasteurizado, indicando sensível redução da comercialização de leite sem inspeção sanitária no Estado, talvez sob os efeitos da Portaria 51, de 2002, e que teve sua aplicação efetivada a partir de 2005.

Os outros subgrupos, queijos e requeijão e outros laticínios, tiveram aumento de consumo nos domicílios paulistas em 2,1\% e 11,0\%, respectivamente, entre 2002-03 e 2008-09. Esse melhor desempenho do consumo dos derivados em relação ao do leite fluido é condizente com análises de Hoffmann [16,17], que estima os valores da elasticidade renda do consumo físico de vários alimentos no Brasil com a POF 2002-03 e a de
2008-09. Esta última revela, nos cálculos do autor, que o consumo físico de leite fluido apresentava elasticidade renda de 0,340 , enquanto que para os diversos tipos de queijo ela ficava entre 0,668 e 0,817 e alcançava 0,545 para o iogurte, em 2008-09.

Embora se esperasse que o consumo de leite fluido em São Paulo mostrasse pequeno crescimento, na realidade os dados aqui analisados registram queda entre 2002-03 e 2008-09, para a qual podem ser levantadas algumas prováveis explicações. A primeira está relacionada com as deficiências dos dados disponíveis, já que não se tem a porcentagem de consumo fora do domicilio de leite fluido especificamente em São Paulo, que pode ser maior do que a aproximação adotada, que é o valor da Região Sudeste. 
Alternativamente, pode-se considerar que de fato essa queda ocorreu, com o leite sendo substituído por outras bebidas, como sucos e refrigerantes. $\mathrm{O}$ trabalho de Hoffmann [17], aliás, mostra que entre as cinco faixas de renda mais alta no Brasil a elasticidade renda do consumo físico de leite se mostrou negativa ($0,021)$, enquanto a elasticidade média para as 10 faixas de renda consideradas se mostrava positiva $(0,340$, como já citado). Como a população de São Paulo tem renda média mais alta que o conjunto das outras unidades da Federação, é possível supor que sua elasticidade renda média seja menor que a nacional, podendo atingir valores negativos.

\section{Quantidade de leite consumida diretamente pelas famílias}

A partir do consumo per capita registrado nas POFs, da participação do consumo dentro e fora do domicílio, da população paulista estimada para 2003 e 2009 e do índice de conversão dos derivados em leite fluido, obteve-se o que se chamou de consumo direto de leite e derivados pelas famílias, cujos valores aparecem na Tabela 11. O consumo total de leite em São Paulo apresentou pequeno aumento entre 2002-03 e 2008-09. Contudo, o consumo per capita anual caiu, de 100,68 kg para 95,42 $\mathrm{kg}^{5}$. Considerando-se a densidade do leite igual a $1,032 \mathrm{~g} / \mathrm{ml}$, chega-se ao consumo per capita de 97,56 litros em 2002-03 e de 92,46 litros em 2008-09.

Segundo recomendações do Ministério da Saúde, citadas por Aleixo [1], o consumo anual recomendável para crianças seria de 146 litros, para jovens de 11 a 19 anos de 256 litros e, para adultos, 219 litros. Embora possam existir subestimativas no consumo apresentado na Tabela 11, seus valores apontam que o consumo de leite no Estado de São Paulo está bem abaixo do recomendável pela Organização Mundial de Saúde e com tendência de queda.

A partir da Tabela 8 e considerando-se a densidade do leite, pode-se calcular que foram industrializadas no Estado, em 2003, 2.428.194,8 toneladas de leite, o que representou $63,0 \%$ do consumo de laticínios pelos paulistas. Já em 2009, foram industrializadas 2.181.462,24 toneladas de leite,

\footnotetext{
5 Para obter esses valores, consideraram-se os dados de Censo Demográfico de 2000 e 2010 e estimou-se que a população paulista era de 38.255.871 pessoas em 2003 e de 40.818 .675 pessoas em $2009{ }^{[18]}$.
}

$56,0 \%$ do consumo estadual. Mesmo sabendo, como revelou a Tabela 8, que 2009 foi particularmente desfavorável para os laticínios em São Paulo, os dados indicaram que cada vez mais o consumo de leite no Estado depende de laticínios e da produção primária de leite de outros Estados.

\section{CONSIDERAÇÕES FINAIS}

O Estado de São Paulo perdeu, de maneira significativa, participação na produção primária e na industrialização do leite no Brasil no período compreendido entre 1990 e 2010. Além disso, o desempenho produtivo da primeira etapa foi menos expressivo que o da industrialização, fazendo com que, nos anos mais recentes, os laticínios paulistas tivessem que captar parte considerável de suas necessidades diárias de leite cru ou resfriado em outros Estados da federação, especialmente Paraná e Minas Gerais. Embora tenha se tornado possível a captação de leite cru ou resfriado em estabelecimentos agropecuários mais distantes dos laticínios, sua proximidade parece se manter como importante fator de competitividade industrial no segmento analisado.

A quantidade de leite industrializada no Estado de São Paulo respondeu, no final do período considerado, por menos de $60,0 \%$ do consumo de lácteos realizado diretamente pelas famílias paulistas. $\mathrm{Na}$ primeira década do século XXI, os dados aqui analisados indicam uma queda no consumo per capita de laticínios pelos paulistas, no âmbito e fora do domicílio. O consumo per capita de leite fluido (na sua grande maioria, pasteurizado) caiu, enquanto crescia o consumo de produtos com maior grau de processamento, os queijos e o iogurte.

Dois fatos estiveram associados à diminuição da produção de leite in natura no Estado de São Paulo. $\mathrm{O}$ primeiro, a redução da área de pastagem, muito significativa na década de 2000 , em decorrência da expansão da lavoura canavieira. $\mathrm{O}$ segundo, o maior direcionamento do rebanho bovino paulista para a produção de carne, em detrimento da pecuária leiteira.

Registraram-se importantes ganhos de produtividade na pecuária leiteira em São Paulo, não suficientes para evitar a perda de sua expressão em nível nacional e, aparentemente, em ritmo menos significativo do que ocorrido na pecuária leiteira no Brasil como um todo. 
Os laticínios paulistas reduziram-se em número e ficaram com maior tamanho médio. Aqueles sob inspeção do SIF são bem maiores que os sob inspeção do SISP ou do SIM. A produção do leite longa vida ou UHT cresceu consideravelmente, mais que a média nacional, enquanto diminuía a produção de leite "barriga mole", de queijo e de leite em pó no Estado de São Paulo.

Tabela 11. Estimativa do consumo familiar anual total de laticínios no Estado de São Paulo, em toneladas, 2002-03 e 2008-09

\begin{tabular}{|c|c|c|c|c|c|}
\hline \multirow{2}{*}{ Produto } & \multirow{2}{*}{$\begin{array}{l}\text { Índice de } \\
\text { Conversão }\end{array}$} & \multicolumn{2}{|c|}{ Consumo 2002-03 } & \multicolumn{2}{|c|}{ Consumo 2008-09 } \\
\hline & & Toneladas & $\%$ & Toneladas & $\%$ \\
\hline Laticínios & & $3.851 .768,7$ & 100,0 & $3.894 .377,2$ & 100,0 \\
\hline Leite e creme de leite & & $2.700 .524,2$ & 70,1 & 2.616.824,9 & 67,2 \\
\hline Creme de leite & 1,0 & $17.841,6$ & 0,5 & $21.046,2$ & 0,5 \\
\hline Leite condensado & 2,5 & $93.357,6$ & 2,4 & $102.943,5$ & 2,6 \\
\hline Leite de vaca fresco & 1,0 & $275.508,6$ & 7,1 & $112.551,6$ & 2,9 \\
\hline Leite de vaca pasteurizado & 1,0 & $1.935 .614,3$ & 50,2 & $1.924 .815,5$ & 49,4 \\
\hline Leite em pó desengordurado & 11,5 & $23.858,0$ & 0,6 & $15.784,6$ & 0,4 \\
\hline Leite em pó integral & 8,5 & $49.375,8$ & 1,3 & $124.447,3$ & 3,2 \\
\hline Leite em pó não especificado & 8,5 & $105.805,2$ & 2,7 & $7.777,9$ & 0,2 \\
\hline Outros leites e cremes & 6,0 & $199.162,8$ & 5,2 & $307.458,0$ & 7,9 \\
\hline Queijos e requeijão & & $906.191,1$ & 23,5 & $1.028 .520,4$ & 26,4 \\
\hline Queijo minas & 8,0 & $175.927,2$ & 4,6 & $212.292,4$ & 5,4 \\
\hline Queijo mozarela & 10,0 & $394.176,5$ & 10,2 & $503.279,5$ & 12,9 \\
\hline Queijo não especificado & 8,0 & $56.429,4$ & 1,5 & $14.640,8$ & 0,4 \\
\hline Queijo parmesão & 13,0 & $48.545,9$ & 1,3 & $71.374,1$ & 1,8 \\
\hline Queijo prato & 10,0 & 107.879,9 & 2,8 & $86.930,1$ & 2,2 \\
\hline Outros queijos & 8,0 & $46.471,3$ & 1,2 & $43.922,5$ & 1,1 \\
\hline Requeijão & 5,0 & $76.760,7$ & 2,0 & $96.080,6$ & 2,5 \\
\hline Outros laticínios & & $245.053,3$ & 6,4 & $249.031,8$ & 6,4 \\
\hline Iogurte & 1,0 & $104.145,5$ & 2,7 & $118.956,9$ & 3,0 \\
\hline Leite fermentado & 0,7 & $19.750,3$ & 0,5 & $34.909,3$ & 0,9 \\
\hline Manteiga & 10,0 & $103.730,6$ & 2,7 & $86.930,1$ & 2,2 \\
\hline Outros & 6,0 & $17.426,7$ & 0,4 & $8.235,4$ & 0,2 \\
\hline
\end{tabular}

Fonte: Aleixo [1]; IBGE [14,15,18]. Obs.: para 2002-03 considerou-se que as despesas com laticínios eram em 92,2\% no domicílio e 7,8\% fora, enquanto em 2008-09 esses valores eram de 89,2\% e 10,8\%.

Há uma política deliberada dos laticínios em estimularem o aumento do tamanho médio dos seus fornecedores de leite in natura, o que acarreta redução de seus custos logísticos. Com o tempo isso pode fazer com que na bovinocultura leiteira, aos moldes do que já ocorre na bovinocultura de corte, deixem de ser predominantes os agricultores familiares [7].
A tendência das últimas duas décadas em São Paulo foi a ampliação da lavoura canavieira, com seus imensos estabelecimentos agropecuários, e o maior direcionamento das pastagens restantes à pecuária bovina de corte.

Entende-se que a recuperação da pecuária bovina leiteira dependa do fortalecimento de políticas públicas, especialmente no campo da comercialização 
de seus produtos, indo além do que já se pratica no Estado e beneficiando mais enfaticamente os agricultores familiares.

Segundo a publicação Leite Brasil ${ }^{[9]}$, em 2005 o Governo Estadual adquiriu, através do Programa Vivaleite, então gerenciado pela Secretaria da Agricultura e Abastecimento, 126 milhões de litros de leite pasteurizado para distribuição em ações sociais, o que correspondeu a 5,5\% da industrialização do leite no Estado. Em 2011, já sob o gerenciamento da Secretaria de Estado de Desenvolvimento Social, foram adquiridos e distribuídos 117 milhões de litros de leite, menos que em $2005^{[19]}$.

\section{Atualmente existem programas} direcionados especificamente à comercialização de alimentos originários da agricultura familiar, como o Programa de Aquisição de Alimentos da Agricultura Familiar, a obrigatoriedade de se gastar no mínimo $30 \%$ das verbas de alimentação escolar distribuídas pelo Fundo Nacional de Alimentação Escolar na compra de produtos oriundos de agricultores familiares, ambos federais, e o Programa Paulista de Agricultura de Interesse Social (PPAIS), fruto de legislação estadual.

Tais programas poderiam ser mais enfaticamente dirigidos ao fortalecimento da produção de leite de vaca em São Paulo, contemplando inclusive sua transformação industrial, especialmente em laticínios de menor porte, cuja presença ainda se constata em praticamente todas as regiões do Estado.

Sob o ponto de vista do consumo, seria interessante que se desenvolvessem programas institucionais de incentivo ao consumo dos laticínios, que, na forma de leite fluido, vem perdendo espaço para outras bebidas, como água mineral, sucos, refrescos e refrigerantes, o que não necessariamente aponta para melhoria nutricional nas refeições dos paulistas.
[1] Aleixo SS. Configurações contemporâneas do complexo agroindustrial do leite: produção, industrialização e consumo no Estado de São Paulo [tese]. Jaboticabal: Universidade Estadual Paulista; 2012. 164 p.

[2] Carvalho GR. A indústria de laticínios no Brasil: passado, presente e futuro. Circular Técnica 1022010 [acesso em 10 dez 2012]. Disponível em: http://www.infoteca.cnptia.embrapa.br/handle/doc/870411

[3] Carvalho GR, Oliveira C. Consolidação na indústria de laticínios: o Brasil no contexto internacional. Agroanalysis. 2010;30(8):20-3.

[4] Azevedo PF, Politi RB. Concorrência e estratégias de precificação no sistema agroindustrial do leite. Rev Econ Sociol Rural. 2008;46(3):767-802.

[5] Fonseca MGD, Morais EM. Indústria de leite e derivados no Brasil: uma década de transformações. Revista do Instituto de Economia Agrícola: Informações Econômicas. 1999;29(9):7-29.

[6] Instituto Brasileiro de Geografia e Estatística (IBGE). Pesquisa Pecuária Municipal. Diversos números [acesso em 10 out 2012]. Disponível em: http://www.sidra.ibge.gov.br/bda/pesquisas/ppm/default.a sp

[7] Baccarin JG. Sistema de produção agropecuário brasileiro: características e evolução recente. São Paulo: Cultura Acadêmica; 2011.

[8] Baccarin JG, Martins MIEG, Aleixo SS. Le Brésil, exportateur de produits et technologies agropastorales. Revue AGIR. 2011;47:87-95.

[9] Leite Brasil. O mapa do leite no Estado de São Paulo. Associação Leite Brasil [Relatório] 2006 [acesso em 01 fev 2012]. Disponível em: http://www.leitebrasil.org.br/mapasp.htm

[10] Instituto de Economia Agrícola. Banco de dados [acesso em 10 out 2012]. Disponível em: http://www.iea.sp.gov.br/out/bancodedados.html

[11] Instituto Brasileiro de Geografia e Estatística (IBGE). Pesquisas Agropecuárias. 2002 [acesso em 06 jan 2012]. Disponível em: http://www.ibge.gov.br/home/estatistica/indicadores/agro pecuaria/PesquisasAgropecuarias2002.pdf

\section{REFERÊNCIAS}


[12] Instituto Brasileiro de Geografia e Estatística (IBGE). Pesquisa Mensal do Leite. Diversos números [acesso em 10

out 2012]. Disponível em:

http://biblioteca.ibge.gov.br/d detalhes.php?id=7204

[13] Instituto Brasileiro de Geografia e Estatística (IBGE). Pesquisa Trimestral do Leite [acesso em 10 out 2012]. Disponível em: http://www.ibge.gov.br/home/estatistica/indicadores/agro pecuaria/producaoagropecuaria/default.shtm\#leite

[14] Instituto Brasileiro de Geografia e Estatística (IBGE). Pesquisa de Orçamentos Familiares 2002-2003 [acesso em 10 out 2012]. Disponível em: http://www.ibge.gov.br/home/xml/pof 2002 2003.shtm

[15] Instituto Brasileiro de Geografia e Estatística (IBGE). Pesquisa de Orçamentos Familiares 2008-2009: análise do consumo alimentar pessoal no Brasil [acesso em 10 out 2012]. Disponível em: http://www.ibge.gov.br/home/estatistica/populacao/condi caodevida/pof/2008 2009 analise consumo/default.shtm

[16] Hoffman R. Elasticidades-Renda das despesas e do consumo físico de alimentos no Brasil Metropolitano em 1995-1996. In: Silveira FG, Servo L, Menezes TA, Piola SF (Org.). Gasto e consumo das famílias brasileiras comteporâneas. Brasília: IPEA; 2007. p. 463-483.

[17] Hoffmann R. Estimativas das elasticidades-renda de várias categorias de despesa e de consumo, especialmente alimentos, no Brasil, com base na POF de 2008-2009. Revista de Economia Agrícola. 2010;57(2):49-62.

[18] Instituto Brasileiro de Geografia e Estatística (IBGE). Banco de dados: dados populacionais [acesso em 10 out 2012]. Disponível em: http://www.sidra.ibge.gov.br/cd/cd2010Serie.asp?o=2\&i=P

[19] Secretaria de Estado de Desenvolvimento Social. Banco de Dados. 2012 [acesso em 15 out 2012]. Disponível em: http://www.desenvolvimentosocial.sp.gov.br/portal.php/viv aleite 